\title{
TP53 Arg 72Pro and XPD Lys751Gln Gene Polymorphisms and Risk of Lung Cancer in Bangladeshi Patients
}

\author{
Tahsin Nairuz ${ }^{1}$, Mostafijur Rahman², Most Umme Bushra ${ }^{3}$, Yearul Kabir ${ }^{2 *}$
}

\begin{abstract}
Background: Tumor suppressor gene (TP53) is considered as the most frequently mutated gene in almost all forms of human cancer. Moreover, genetic variations in the XPD gene affect the DNA repair capacity increasing cancer susceptibility. Polymorphisms within these genes can play a major role in determining individual lung cancer susceptibility. However, several studies have investigated this possibility; but reported conflicting results. Therefore, the objective of this study was to investigate the role of TP53 Arg72Pro and XPD Lys751Gln gene polymorphisms on lung cancer susceptibility in the Bangladeshi population. Materials and Methods: Study subjects comprised of 180 lung cancer patients and 200 healthy volunteers. Genetic polymorphism of TP53 was determined by multiplex PCRbased method, while XPD genotypes were analyzed using Polymerase Chain Reaction-based Restriction Fragment Length Polymorphism (PCR-RFLP) method. Lung cancer risk was estimated as odds ratio (OR) and 95\% confidence interval (CI). Results: From the results, no significant association between TP53 Arg72Pro polymorphism and lung cancer risk was observed. Whereas, patients with homozygous mutant variants (Gln/Gln) of XPD at codon 751 were found significantly associated with lung cancer risk when compared to the control $(\mathrm{OR}=3.58 ; 95 \% \mathrm{CI}=1.58-8.09$; $\mathrm{p}=0.002)$. Lung cancer risk was found significantly higher with $\mathrm{Gln} / \mathrm{Gln}$ variants of XPD among smokers $(\mathrm{OR}=4.03$; 95\% CI=1.11-14.63; $\mathrm{p}=0.026)$. Significant increased risk of lung cancer was found with Arg/Pro genotypes of TP53, Lys/Gln and Gln/Gln variants of XPD in individuals with family history of cancer (OR=3.44; 95\% CI=1.36-8.72; $\mathrm{p}=0.011 ; \mathrm{OR}=3.17 ; 95 \% \mathrm{CI}=1.20-8.39 ; \mathrm{p}=0.024 ; \mathrm{OR}=16.35 ; 95 \% \mathrm{CI}=0.92-289.5 ; \mathrm{p}=0.007$, respectively). Conclusion: The findings indicated that homozygous mutant variants $(\mathrm{Gln} / \mathrm{Gln})$ of XPD were associated with increased lung cancer risk, whereas TP53 Arg72Pro polymorphism was not associated with risk of lung cancer among Bangladeshi patients.
\end{abstract}

Keywords: Lung cancer- XPD- TP53- PCR-RFLP- genetic polymorphism

Asian Pac J Cancer Prev, 21 (7), 2091-2098

\section{Introduction}

Lung cancer is one of the most prevalent malignancies with the largest number of patients all over the world. Worldwide, 2.1 million cases are newly diagnosed with lung cancer $(11.6 \%$ of the total cases) and it is regarded as the leading cause of cancer death $(18.4 \%$ of the total cancer deaths) predicted in 2018 (GLOBOCAN) (Bray et al., 2018). In Bangladesh, lung cancer ranks as the top prevalent cancer in males considering incidence and mortality (24.9\% of incidence and $28.6 \%$ of mortality), whereas in case of females, the incidence of lung cancer $(5.6 \%)$ is next to breast cancer $(21.9 \%)$, cervical cancer $(21.8 \%)$ and lip \& oral cavity cancer $(6.6 \%)$ and mortality of lung cancer $(7.6 \%)$ is next to cervical $(19 \%)$ and breast cancer (15.4\%) (Ferlay et al., 2010). In Bangladesh, the total number of lung cancer patients was estimated to be 196,000 and $85 \%$ of those are aged 30 years or above
(Hussain and Sullivan, 2013). The recent WHO data of 2017 anticipated that in Bangladesh lung cancer deaths reached 12,075 or $1.53 \%$ of total deaths (WHO, 2017). Moreover, the new cases of lung cancer in Bangladesh were recorded 14951 in 2008 and the annual number of cases is supposed to reach 43,048 by 2030 stated by IARC 2010 report (Hussain and Sullivan, 2013).

The development and progression of lung cancer are complex, multilateral, and multifactorial process. The well-established major risk factors for lung cancer are exposure to cigarette smoke and other environmental carcinogens where about $80-90 \%$ of lung cancers are attributable to cigarette smoking (Mustafa et al., 2016). Even though the carcinogenic consequences of smoking and alcohol consumption are evident, not all exposed individuals develop lung cancer which demonstrates that other factors including genetic polymorphisms may also alter the risk of this fatal disease independently or in

${ }^{1}$ Department of Biochemistry and Molecular Biology, Noakhali Science and Technology University, Bangladesh. ${ }^{2}$ Department of Biochemistry and Molecular Biology, University of Dhaka. Bangladesh. ${ }^{3}$ Department of Pharmacy, Manarat International University, Bangladesh.*For Correspondence: ykabir@yahoo.com 
combination with each other along with the environmental exposures (Kiyohara et al., 2006; Steliga and Dresler, 2011; Torok et al., 2011).

The tumor suppressor gene p53 (TP53), is located on chromosome $17 \mathrm{p} 13$, is the most frequently mutated genes in human cancer. TP53 gene inactivation is thought to be a key contributor in the early event of lung carcinogenesis (Takahashi et al., 1989). Mutations in the TP53 gene contribute to $>90 \%$ of small cell lung cancers and $>50 \%$ of non-small cell lung cancers (Nigro et al., 1989; Vousden, 2000; Yokota and Kohno, 2004). The codon 72 polymorphism ( $r s$ 1042522) on the $4^{\text {th }}$ exon of the TP53 gene was found to have an association with lung cancer (Weston et al., 1993). This polymorphism generates variant proteins with an arginine (CGC) or proline (CCC) that modifies $\mathrm{p} 53$ protein ability to induce apoptosis, influences the action of mutant $\mathrm{p} 53$, reduces DNA repair efficacy and thus may be increased the risk of lung cancer. From a meta-analysis of thirteen epidemiologic investigations, the odds ratio of lung cancer related to the Pro/Pro genotype and Pro-carrier was found 1.18 (95\% CI $0.99-1.41)$ and was 1.02 (95\% CI 0.86-1.20) respectively (Matakidou et al., 2003). In lung cancer patients, the Pro/ Pro genotype has also been related to poorer prognosis and less conducive clinical outcomes (Han et al., 2008; Nelson et al., 2005; Wang et al., 1999). Furthermore, a significantly higher or lower incidence of p53 gene mutations has been found in the Polish (Szymanowska et al., 2006) or a Norwegian population (Lind et al., 2007), respectively, among lung cancer carriers of the Pro allele. These findings highlight that corresponding to SNP and mutational status, ethnicity, and some other factors can have a great influence on p53 functionality.

Moreover, interindividual differences in lung cancer susceptibility may also be modified in part through polymorphisms in the DNA repair genes, especially those involved in the nucleotide excision repair (NER) pathway. The Xeroderma Pigmentosum Complementary group D $(X P D)$ is one of the genes involved in nucleotide excision repair with an impact in p53-dependent apoptosis. XPD gene polymorphism at position 751 in exon 23 ( $r s 13181$ ) resulting in a lysine-to-glutamine transition, may alter the interactions of different proteins, reduce the activity of TFIIH complexes and modulate the genetic susceptibility for cancer. Several studies failed to investigate an increased risk of lung cancer with XPD Lys $751 \mathrm{Gln}$ polymorphism (David-Beabes et al., 2001; Park et al., 2002), whereas other reports observed an association of lung cancer risk with variant alleles in XPD (Liang et al., 2003; Zhou et al., 2002). These inconsistent associations in previous studies might be caused by differences in study populations, possible environmental interactions, and inadequate sample sizes of earlier studies.

In Bangladesh, lung cancer ranks as the top prevalent cancer in males (Uddin et al., 2013). However, the genetic polymorphisms that are responsible for increased susceptibility to lung cancer need to be given priority to reduce the ensuing lung cancer morbidity and mortality in Bangladesh. Considering the potential association of TP53 and $X P D$ gene polymorphisms with lung cancer, several studies have conducted in different populations. Although a limited study related to TP53 Arg72Pro polymorphism has been done in the Bangladeshi population, this study adds novel evidence on the prospective association of TP53 Arg72Pro polymorphism with a family history of lung cancer. Moreover, this is the first study on XPD Lys 751 Gln polymorphism with Bangladeshi lung cancer patients. Therefore, the objective of this study was to investigate the possible association of TP53 and XPD gene polymorphisms with the risk of developing lung cancer and its aggressiveness as well as smoking impact in the Bangladeshi population.

\section{Materials and Methods}

\section{Study design}

The study was designed as a case-control study with 180 lung cancer patients (cases) and 200 healthy volunteers (controls). Patients diagnosed histologically with lung cancer as per the International Association of Lung Cancer (Travis, 2011) and aged between 40 and 85 years were considered as cases and they were selected from three major cancer treatment-based hospitals in Bangladesh (Ahsania Mission Cancer and General Hospital, Dhaka Medical College Hospital, and Bangabandhu Sheikh Mujib Medical University). Controls were chosen following a physical examination and those with a previous history or any record of other severe diseases such as kidney disease, cardiovascular disease, and metastasized cancer were eliminated from the study. They were recruited from the Dhaka University Medical Centre, Department of Biochemistry and Molecular Biology, University of Dhaka, Kobi Sufia Kamal Hall, Dhaka University, Bangladesh Institute of Research and Rehabilitation in Diabetes, Endocrine and Metabolic Disorder (BIRDEM), Popular Diagnostics Center, Dhanmondi, Dhaka. All participants were explained about the purpose of the study and their written consent was taken. They filled up a structured questionnaire regarding the information on age, gender, smoking history, pathological tumor stage, and family history of chronic diseases. The protocol was approved by the Ethical Review Committees of the Department of Biochemistry and Molecular Biology, University of Dhaka, and the study was carried out according to the declaration of Helsinki and its subsequent revisions (WMA, 2013).

\section{Sample collection}

After taking necessary aseptic precautions approximately $3.0 \mathrm{~mL}$ venous blood was collected from all cases and controls with a disposable syringe. The collected sample was immediately transferred to EDTA containing tube $(1.20 \mathrm{mg} / \mathrm{mL})$ and then transported to the laboratory by keeping in an icebox. Until DNA extraction, the blood samples were refrigerated at $-20^{\circ} \mathrm{C}$.

\section{DNA extraction and Genotyping}

The extraction of genomic DNA from blood samples was done through the organic extraction procedure described by Bailes et al., (2007). Genotyping of TP53 was analyzed by allele-specific multiplex PCR assay which selectively identifies the presence of either Arg or 
Pro p53 allele. The PCR assay was performed individually for each of the two polymorphic alleles. $\beta$-globin gene was amplified in both reactions as an internal positive control for ensuring successful PCR. On the other hand, XPD genotyping was done by PCR-Restriction Fragment Length Polymorphism (RFLP) method. The PCR conditions and primer sequences were used from the previously published papers (Mitra et al., 2009; Paoadakis et al., 2002). The co-amplified PCR products of TP53 were resolved in $2 \%$ agarose gel following ethidium bromide staining, whereas that of XPD was analyzed with RFLP using the restriction enzyme PstI. The optional size of the product was ascertained by comparing it with the DNA ladder. For TP53, the Arg allele and Pro allele were determined by the presence of $199 \mathrm{bp}$ and $177 \mathrm{bp}$ PCR amplified products respectively (Figures 1 and 2). For the XPD genotype, fifteen microliters of PCR product (413 bp) were digested at $37^{\circ} \mathrm{C}$ for 16 hours in a water bath with the respective restriction enzyme. The enzyme digestion product was analyzed on 3\% agarose gel and visualized using a gel documentation system following ethidium bromide staining (Figure 3). Upon restriction digestion, the homozygous wild type (AA) genotype produced a single band of $413 \mathrm{bp}$, the homozygous mutant genotype (CC) generated two bands of $322 \mathrm{bp}$ and $91 \mathrm{bp}$, and the heterozygous genotype (AC) indicated three bands of 413 bp, $322 \mathrm{bp}$ and $91 \mathrm{bp}$ (Figure 4).

\section{Statistical analysis}

Statistical analyses were done through SPSS Windows version 24 . The relative association between cases and controls was measured by calculating the odds ratio (OR). By using logistic regression models OR, as a measure of relative risk, were estimated at $95 \%$ confidence intervals (95\% CI). Fisher's and chi-square tests were assessed by GraphPad Prism, version-7. A p-value of less than 0.05 was regarded as a level of significance.

\section{Results}

\section{Characteristics of the study subjects}

The baseline characteristics of the study subjects according to age, gender, smoking status, family history
TP53 and XPD Polymorphisms in Lung Cancer of cancer are presented in Table 1. Briefly, no significant differences were found in the mean age between the two groups. On the other hand, the result of demographic data shows significant differences in gender, smoking status, and family history of cancer among study subjects $(p<0.001)$. Present and ex-smokers were regarded as ever smokers, whereas persons who had never smoked at the periods of his/her lifetime were considered as never smokers.

Frequency distribution of TP53 and XPD genotype and risk of lung cancer

The frequency distribution of TP53 Arg72Pro and XPD Lys751Gln genotypes in control and patient with their estimated risk of lung cancer is presented in Table 2. In lung cancer patients, the frequency of arginine homozygous (Arg/Arg), proline homozygous (Pro/Pro), and arginine/proline heterozygous (Arg/Pro) was found $37 \%, 5 \%$ \& $58 \%$ respectively. Whereas, in controls, the frequency of arginine homozygous (Arg/Arg), proline homozygous (Pro/Pro) and arginine/proline heterozygous (Arg/Pro) was $36.67 \%, 7.22 \%$ \& 56.11\% respectively. No significant differences were present in the frequency distribution of proline homozygous (Pro/Pro) $(\mathrm{OR}=$ $0.976,95 \% \mathrm{CI}=0.64-1.50, \mathrm{p}=0.501)$ and arginine/proline heterozygous ( $\mathrm{Arg} / \mathrm{Pro})(\mathrm{OR}=1.458,95 \% \mathrm{CI}=0.60-3.55$, $\mathrm{p}=0.914$ ) between controls and lung cancer patients, when Arg/Arg was considered as reference group.

On the other hand, among 180 patients of lung carcinoma, homozygous wild type (Lys/Lys) was $44.44 \%$, heterozygous mutant variant (Lys/Gln) was $41.67 \%$ and homozygous mutant variant $(\mathrm{Gln} / \mathrm{Gln})$ was $13.89 \%$. Whereas in controls, $51.50 \%$ was homozygous wild type (Lys/Lys), 44\% was heterozygous mutant variant (Lys/ Gln) and $4.50 \%$ was homozygous mutant variant (Gln/ Gln). Patients with homozygous mutant variants (Gln/ Gln) of XPD at codon 751 were found significantly associated with lung cancer risk when compared to the control $(\mathrm{OR}=3.58 ; 95 \% \mathrm{CI}=1.58-8.09 ; \mathrm{p}=0.002)$, whereas no significant association was found with heterozygous mutant variants $(\mathrm{Lys} / \mathrm{Gln})(\mathrm{OR}=1.10 ; 95 \% \mathrm{CI}=0.72-1.68$; $\mathrm{p}=0.745)$ when Lys/Lys was considered as a reference group.

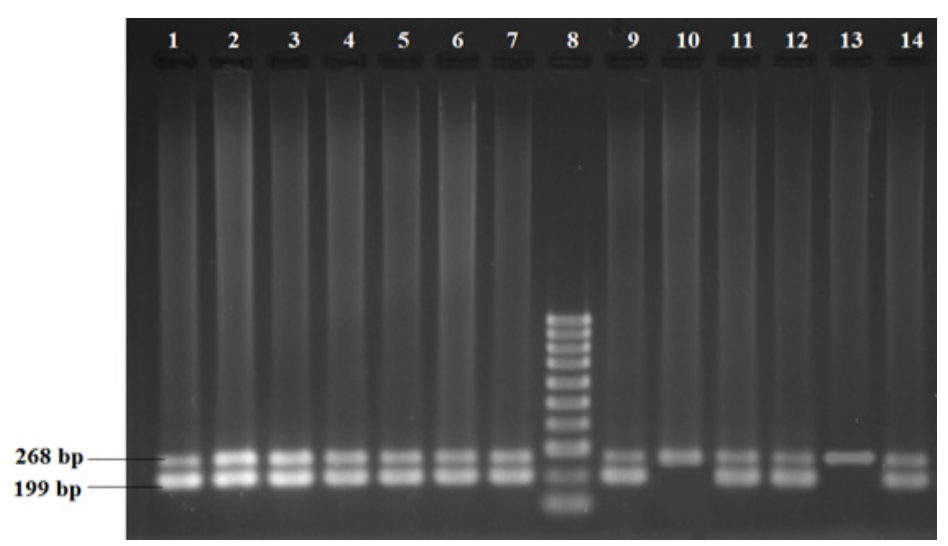

Figure 1. Multiplex-PCR Analysis of Arginine Specific Exon of TP53 Gene Polymorphism. Arginine specific exon of TP53 (199bp), internal control $\beta$-globin (268bp). Lane 1-7,9,11,12,14 indicates the presence of arginine specific exon of the TP53 gene. Lane 10,13 represents individuals who are negative for this specific exon of the TP53 gene. Lane 8 indicates the molecular marker of the $100 \mathrm{bp}$ ladder. 


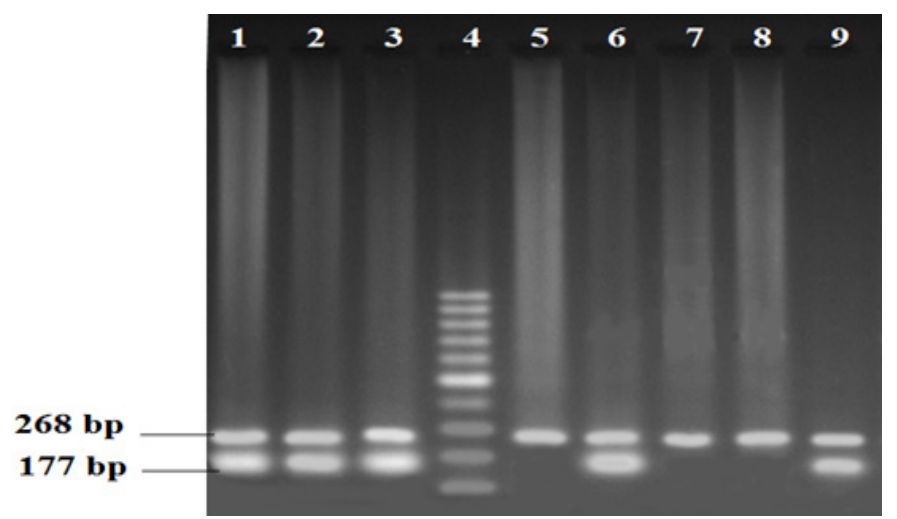

Figure 2. Multiplex-PCR Analysis of Proline Specific Exon of TP53 Gene Polymorphism. Proline specific exon of TP53 (177bp), internal control $\beta$-globin (268bp). Lane 1-3,6,9 indicates the presence of proline specific exon of the TP53 gene. Lane 5,7,8 represents individuals who are negative for this specific exon of the TP53 gene. Lane 4 indicates the molecular marker of the $100 \mathrm{bp}$ ladder.

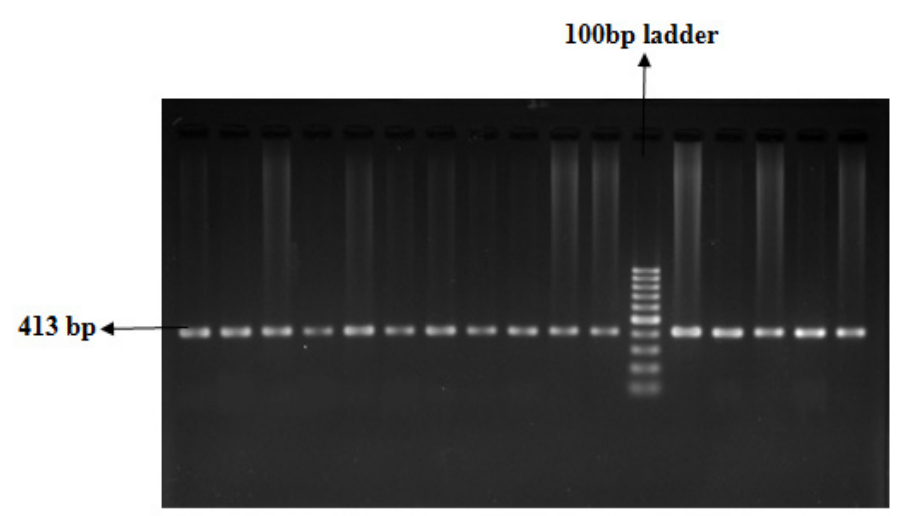

Figure 3. Representative PCR Products of the XPD Gene in $2 \%$ Agarose Gel

TP53 and XPD genotype on risk of lung cancer according to smoking status and family history of lung cancer

Association of TP53 and XPD genotypes and lung cancer risk according to smoking status and family history are shown in Table 3 . The risk of developing lung cancer was low for both smokers and nonsmokers with Arg/Pro genotype. Whereas, the frequency of Pro/Pro genotype was found nonsignificantly higher $(\mathrm{OR}=2.88$; $95 \% \mathrm{CI}=0.64-12.87 ; \mathrm{p}>0.05)$ in nonsmoker lung cancer patients compared to control. In the case of XPD, lung cancer risk was low for both smokers and nonsmokers with Lys/Gln genotype. Whereas, the frequency of Gln/ Gln genotype was significantly higher $(\mathrm{OR}=4.03 ; 95 \%$ $\mathrm{CI}=1.11-14.63 ; \mathrm{p}=0.026)$ in smoker lung cancer patients compared to control.

In the case of a family history of cancer, the frequency of the Arg/Pro genotype was found significantly higher in lung cancer patients having a family history of cancer

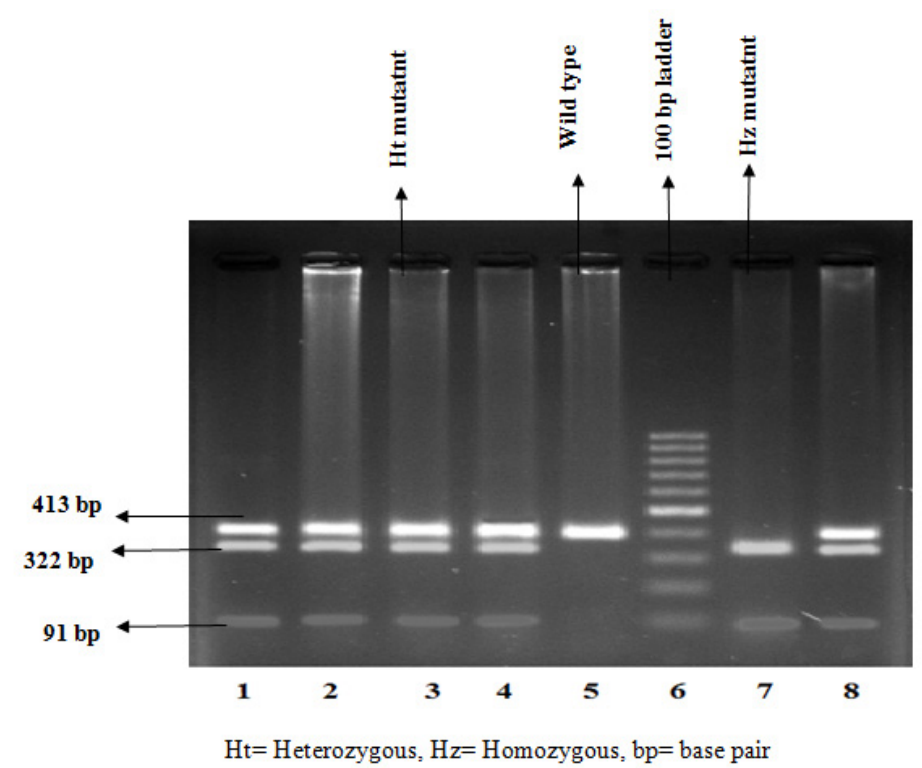

Figure 4. Representative Picture of Digestion of XPD by PstI in 3\% Agarose Gel 
Table 1. Baseline Characteristics of the Study Subject

\begin{tabular}{lccc}
\hline Variable & $\begin{array}{c}\text { Control } \\
(\mathrm{n}=200) \\
\mathrm{n}(\%)\end{array}$ & $\begin{array}{c}\text { Patient } \\
(\mathrm{n}=180) \\
\mathrm{n}(\%)\end{array}$ & $P$-value \\
\hline Age (Years) & $66(33.00)$ & $43(23.88)$ & \\
$<50$ & $129(64.50)$ & $126(70.00)$ & \\
$50-70$ & $5(2.50)$ & $11(6.11)$ & \\
$>70$ & $54.70 \pm 0.55$ & $55.83 \pm 0.66$ & $\mathrm{~ns}$ \\
Age (Mean \pm SEM) & & & \\
Gender & $155(77.50)$ & $109(60.56)$ & \\
Male & $45(22.50)$ & $71(39.44)$ & $<0.001$ \\
Female & & & \\
Smoking status & $125(62.50)$ & $52(28.89)$ & \\
Never & $75(37.50)$ & $128(71.11)$ & $<0.001$ \\
Ever & & & \\
Family history of cancer & & \\
Yes & $28(14.00)$ & $85(47.22)$ & \\
No & $172(86.00)$ & $95(52.78)$ & $<0.001$
\end{tabular}

Fisher's and chi-square tests were done to calculate the statistical significance; $\mathrm{p}<0.05$ considered as a level of significance; ns, not significant

compared to control $(\mathrm{OR}=3.44,95 \% \mathrm{CI}=1.36-8.72$, $\mathrm{p}=0.011$ ). On the other hand, none of the variants were found significantly associated with lung cancer risk in case of having no family history of cancer. On the other hand, the frequency of Lys/Gln and Gln/Gln variants of XPD was significantly higher in cancer patients having a family history of cancer compared to control $(\mathrm{OR}=3.17 ; 95 \% \mathrm{CI}=1.20-8.39 ; \mathrm{p}=0.024 ; \mathrm{OR}=16.35$; $95 \% \mathrm{CI}=0.92-289.5 ; \mathrm{p}=0.007$ respectively). None of the variants were found significantly associated with lung cancer risk in case of having no family history of cancer.

In this study, the frequencies of TP53 and XPD genotype in the lung cancer patients according to tumor stage IIIA and IIIB (Lung cancer stage group accordance with TNM classification) (Liu and Zhi, 2015) were also analyzed but no significant association of these polymorphisms with tumor stages was observed. Similarly, the analysis of pairwise joint associations of TP53 Arg72Pro and XPD Lys751Gln genotypes with lung cancer risk showed the statistically non-significant result, although the odds ratios of combined mutant or deficient variants of the studied genes were higher in lung cancer patients than controls.

\section{Discussion}

TP53 and XPD Polymorphisms in Lung Cancer

This population-based case-control study was carried out to evaluate the association of Tumor suppressor gene p53 (TP53) and Xeroderma Pigmentosum Complementary Group D (XPD) gene polymorphisms on lung cancer susceptibility in the Bangladeshi population. Worldwide, numerous studies investigating the role of TP53 and XPD gene polymorphisms with lung cancer have prompted to inconsistent reports, even though several studies have identified that individuals polymorphic for the tumor suppressor or DNA repair genes are increased the risk for developing lung cancer. For this study, we had undertaken 180 lung cancer patients and 200 healthy controls where both patients and healthy controls belonged to the same ethnic background and all shared a common geographic origin. The results of basic demographic data showed significant differences in gender, smoking status, and family history of cancer (Table 1).

The distribution of the three genotypes of TP53, Arg/ Arg, Arg/Pro, and Pro/Pro was found 36.67\%, 56.11\% and $7.22 \%$ in lung cancer patients compared to $37 \%, 58 \%$ and $5 \%$ in healthy control respectively (Table 2 ). These results indicated no statistically significant association of Arg/Pro or Pro/Pro genotype with increased risk of developing lung cancer when Arg/Arg was considered as a reference group, that is consistent with the results reported by Jung et al. (2008) and Mechanic et al. (2007). Although, Chowdhury et al. (2015) and Mostaid et al. (2014) noted a significant association of TP53 Arg72Pro gene polymorphism with lung cancer susceptibility in the Bangladeshi population, the inconsistency result between our study with that of previous two studies may be related to the sample size, differences in histological type and clinical stages of lung cancer as well as the age of the study subjects (cancer patients) between their study populations (Chowdhury et al., 2015; Mostaid et al., 2014) and ours.

In contrast to tumor suppressor gene TP53, a significant association was found between DNA repair gene $X P D$ Lys 751 Gln polymorphism and risk of lung cancer. Patients with homozygous mutant variants (Gln/Gln) of XPD were found significantly associated with a 3.6 fold increased risk of lung cancer compared to the control ( $\mathrm{OR}=3.58$; 95\% CI=1.58-8.09; $\mathrm{p}=0.002$ ), whereas no significant association was found with heterozygous mutant variants (Lys/Gln) (Table 2). These findings are compatible with a previous case-control study that found a significant

Table 2. Genotypic Distribution of TP53 (codon 72) and XPD (codon 751) in the Study Subject and Risk of Lung Cancer

\begin{tabular}{llcccc}
\hline Gene & Genotype & Control $(\mathrm{n}=200)$ & Patient (n=180) & OR (95\% CI) & $P$-value \\
& & $\mathrm{n}(\%)$ & $66(36.67)$ & 1.0 (Ref.) & \\
\hline TP53 & Arg/Arg & $74(37.00)$ & $101(56.11)$ & $0.976(0.64-1.50)$ & 0.914 \\
& Arg/Pro & $116(58.00)$ & $13(7.22)$ & $1.458(0.60-3.55)$ & 0.501 \\
& Pro/ Pro & $10(5.00)$ & $80(44.44)$ & 1.0 (Ref.) & \\
XPD & Lys/Lys & $103(51.50)$ & $75(41.67)$ & $1.097(0.72-1.68)$ & 0.745 \\
& Lys/Gln & $88(44.00)$ & $25(13.89)$ & $3.576(1.58-8.09)$ & $0.002^{*}$ \\
\hline
\end{tabular}

Odds ratios $(\mathrm{OR})$ and $95 \%$ confidence interval $(95 \% \mathrm{CI}) ;{ }^{*} \mathrm{p}<0.05$ considered as level of significance. 
Table 3. TP53 and XPD Genotype on Risk of Lung Cancer According to Smoking Status and Family History of Cancer

\begin{tabular}{|c|c|c|c|c|c|c|}
\hline Smoking Status/ Family History of Cancer & Gene & Genotype & $\begin{array}{l}\text { Control } \\
(n=200)\end{array}$ & $\begin{array}{l}\text { Patient } \\
(\mathrm{n}=180)\end{array}$ & OR $(95 \% \mathrm{CI})$ & $P$-value \\
\hline & & Arg/Arg & 28 & 50 & 1.0 (Ref.) & - \\
\hline \multirow[t]{4}{*}{ Smoker } & & Arg/Pro & 41 & 69 & $0.94(0.52-1.72)$ & ns \\
\hline & & Pro/ Pro & 6 & 9 & $0.84(0.27-2.61)$ & ns \\
\hline & TP53 & & & & & \\
\hline & & Arg/Arg & 46 & 16 & 1.0 (Ref.) & - \\
\hline \multirow[t]{3}{*}{ Non Smoker } & & Arg/Pro & 75 & 32 & $1.23(0.61-2.48)$ & ns \\
\hline & & Pro/Pro & 4 & 4 & $2.88(0.64-12.87)$ & ns \\
\hline & & Lys/Lys & 39 & 58 & 1.0 (Ref) & - \\
\hline \multirow[t]{4}{*}{ Smoker } & & Lys/Gln & 33 & 52 & $1.06(0.58-1.92)$ & ns \\
\hline & & $\mathrm{Gln} / \mathrm{Gln}$ & 3 & 18 & $4.03(1.11-14.63)$ & $0.026^{*}$ \\
\hline & $X P D$ & Lys/Lys & 64 & 22 & 1.0 (Ref) & - \\
\hline & & Lys/Gln & 55 & 23 & $1.22(0.61-2.42)$ & ns \\
\hline \multirow[t]{2}{*}{ Non Smoker } & & $\mathrm{Gln} / \mathrm{Gln}$ & 6 & 7 & $3.39(1.03-11.19)$ & ns \\
\hline & & Arg/Arg & 17 & 28 & 1.0 (Ref.) & - \\
\hline \multirow[t]{3}{*}{ Yes } & & Arg/Pro & 9 & 51 & $3.44(1.36-8.72)$ & $0.011^{*}$ \\
\hline & & Pro/Pro & 2 & 6 & $1.82(0.33-10.07)$ & ns \\
\hline & TP53 & & & & & \\
\hline \multirow[t]{4}{*}{ No } & & Arg/Arg & 57 & 38 & 1.0 (Ref.) & - \\
\hline & & Arg/Pro & 107 & 50 & $0.70(0.41-1.19)$ & ns \\
\hline & & Pro/ Pro & 8 & 7 & $1.31(0.44-3.92)$ & ns \\
\hline & & Lys/Lys & 21 & 35 & 1.0 (Ref.) & - \\
\hline \multirow[t]{3}{*}{ Yes } & & Lys/Gln & 7 & 37 & $3.17(1.20-8.39)$ & $0.024 *$ \\
\hline & & $\mathrm{Gln} / \mathrm{Gln}$ & 0 & 13 & $16.35(0.92-289.5)$ & $0.007 *$ \\
\hline & $X P D$ & & & & & \\
\hline \multirow[t]{3}{*}{ No } & & Lys/Lys & 82 & 45 & 1.0 (Ref.) & - \\
\hline & & Lys/Gln & 81 & 38 & $0.85(0.50-1.45)$ & ns \\
\hline & & $\mathrm{G} \ln / \mathrm{G} \ln$ & 9 & 12 & $2.43(0.95-6.21)$ & ns \\
\hline
\end{tabular}

Odds ratios (OR) and $95 \%$ confidence interval $(95 \% \mathrm{CI}) ;{ }^{*} \mathrm{p}<0.05$ considered as level of significance; ns, not significant

association of XPD Lys 751 Gln gene polymorphism with an increased risk of developing lung cancer (Zhou et al., 2002; Liang et al., 2003). Whereas, several studies failed to identify an association of the XPD Lys $751 \mathrm{Gln}$ polymorphism with lung cancer (David-Beabes et al., 2001; Park et al., 2002). The inconsistent results in several studies for the $X P D$ polymorphisms might be attributable to differences in ethnicities, selected study subjects, the small sample size, and probable environmental interactions.

Exploring the association of smoking status, tumor stage, and family history of cancer with genotypes and lung cancer risk, no significant increased risk of lung cancer was found in smokers in the case of TP53 genotypes (Table 3 ). This result is consistent with that reported by Wang et al. (2013). Kawajiri et al. also anticipated that $p 53$ polymorphism modifies smokinginduced lung cancer risk independently of other genetic risk factors (Kawajiri et al., 1993). In the case of XPD Lys 751 Gln gene polymorphism, the frequency of the Gln/Gln variant significantly higher was found in smoker lung cancer patients compared to nonsmokers (Table 3). Similarly, Zhou et al. found that smoking could modulate the impacts of XPD gene polymorphisms on lung cancer risk, suggesting a gene-environmental influence in lung carcinogenesis (Zhou et al., 2003).

Significant increase risk of lung cancer with Arg/Pro genotype of TP53, Lys/Gln and Gln/Gln variants of XPD was found in individuals with a family history of cancer (Table 3), which revealed that family history of cancer may be a risk factor for patients having these gene variants. On the contrary, no significant association of TP53 (codon 72) and $X P D$ gene polymorphisms was observed with stage IIIA and IIIB lung cancer patients which signified that there was no association between these genotypes and the frequency of more aggressive tumor. 
Considering that different combined polymorphisms were related to a more increased risk of cancer, the TP53 and $X P D$ genotype combinations were also analyzed in this study for correlations with the increased risk of lung cancer, but these results are not statistically significant. The lack of statistical significance in this study may be due to the selection of different pathway genes that are not interrelated or inadequate sample size.

In conclusion, our study suggested a prospective association of genetic polymorphisms with increased susceptibility to lung cancer. The study revealed that $G \ln / G l n$ variants at codon 751 of $X P D$ are associated with the susceptibility of lung cancer, whereas TP53 Arg72Pro gene polymorphism is not associated with increased risk of developing lung cancer in Bangladeshi population. Considering the genetic backgrounds of the study subjects, the results may be attributed to taking an individualized therapeutic decision in lung cancer. Nevertheless, this study had a small sample size hence, further studies with a large sample size are needed to determine the true impact of genetic susceptibility in lung cancer in Bangladesh.

Authors' Contribution: Tahsin Nairuz designed and implemented the study, performed data analysis, and drafted the paper. Md. Mostafijur Rahman assisted in implementation and data analysis. Most Umme Bushra follows up patients' enrollment, helps in sample collection and data management. Yearul Kabir provided overall guidance and support to the study and critically reviewed the manuscript. All authors have read and approved the final manuscript. None of the authors had a personal or financial conflict of interest.

\section{Acknowledgments}

Authors thank physicians and nurses of Ahsania Mission Cancer and General Hospital, Dhaka Medical College Hospital, and Bangabandhu Sheikh Mujib Medical University, Dhaka, Bangladesh for their technical assistance during blood collection and patient counseling. We also thank all the study subjects for participating in this study. The authors are thankful to Dr. Noor Ahmed Nahid, Department of Clinical Pharmacy and Pharmacology, University of Dhaka, for helping to collect the patients' samples. The authors are also thankful to all the members of the Institutional Ethical Review Committees of the Department of Biochemistry and Molecular Biology, University of Dhaka, Bangladesh for approval of the study protocol. This research did not receive any funding.

\section{References}

Bailes SM, Devers JJ, Kirby JD, Rhoads DD (2007). An inexpensive, simple protocol for DNA isolation from the blood for high-throughput genotyping by polymerase chain reaction or restriction endonuclease digestion. Poult Sci, 86, 102-6.

Bray F, Ferlay J, Soerjomataram I, et al (2018). Global cancer statistics 2018: GLOBOCAN estimates of incidence and mortality worldwide for 36 cancers in 185 countries. $C A$ Cancer J Clin, 68, 394-424.

Chowdhury MK, Moniruzzaman M, Emran AA, et al (2015). TP53 codon 72 polymorphisms and lung cancer risk in
TP53 and XPD Polymorphisms in Lung Cancer the Bangladeshi population. Asian Pac J Cancer Prev, 16, 3493-8.

David-Beabes GL, Lunn RM, London SJ (2001). No association between the XPD (Lys751G1n) polymorphism or the XRCC3 (Thr241Met) polymorphism and lung cancer risk. Cancer Epidemiol Biomarkers Prev, 10, 911-2.

Ferlay J, Shin HR, Bray F, et al (2010). Estimates of worldwide burden of cancer in 2008: GLOBOCAN 2008. Int J Cancer, 127, 2893-917.

Han JY, Lee GK, Jang DH, Lee SY, Lee JS (2008). Association of p53 codon 72 polymorphism and MDM2 SNP309 with clinical outcome of advanced nonsmall cell lung cancer. Cancer, 113, 799-807.

Hussain SA, Sullivan R (2013). Cancer control in Bangladesh. Jpn J Clin Oncol, 43, 1159-69.

Jung H-Y, Whang YM, Sung JS, et al (2008). Association study of TP53 polymorphisms with lung cancer in a Korean population. J Hum Genet, 53, 508-14.

Kawajiri K, Nakachi K, Imai K, Watanabe J, Hayashi S (1993). Germ line polymorphisms of $\mathrm{p} 53$ and CYP1A1 genes involved in human lung cancer. Carcinogenesis, 14, 1085-9.

Kiyohara C, Yoshimasu K, Takayama K, Nakanishi Y (2006). EPHX1 polymorphisms and the risk of lung cancer: a huge review. Epidemiology, 17, 89-99.

Liang G, Xing D, Miao X, et al (2003). Sequence variations in the DNA repair geneXPD and risk of lung cancer in a Chinese population. Int J Cancer, 105, 669-73

Lind H, Ekstrom H, Ryberg PO, et al (2007). Frequency of TP53 mutations in relation to Arg72Pro genotypes in nonsmall cell lung cancer. Cancer Epidemiol Biomarkers Prev, 16, 2077-81.

Liu BD, Zhi XY (2015). Expert consensus on image-guided radiofrequency ablation of pulmonary tumors - 2015 edition. Ann Transl Med, 3, 128.

Matakidou A, Eisen T, Houlston RS (2003). TP53 polymorphisms and lung cancer risk: a systematic review and meta-analysis. Mutagenesis, 18, 377-85.

Mechanic LE, Bowman ED, Welsh JA, et al (2007). Common genetic variation in TP53 is associated with lung cancer risk and prognosis in African Americans and somatic mutations in lung tumors. Cancer Epidemiol Biomarkers Prev, 16, 214-22.

Mitra AK, Singh N, Garg VK, et al (2009). Statistically significant association of the single nucleotide polymorphism (SNP) rs13181 (ERCC2) with predisposition to squamous cell carcinomas of the head and neck (SCCHN) and breast cancer in the north Indian population. J Exp Clin Cancer Res, 28, 104.

Mostaid MS, Ahmed MU, Islam MS, et al (2014). Lung cancer risk in relation to TP53 codon 47 and codon 72 polymorphism in Bangladeshi population. Tumor Biol, 35, 10309-17.

Mustafa M, Azizi ARJ, IIIzam EL, et al (2016). Lung cancer: risk factors, management, and prognosis. J Dent Med Sci, 15, 94-101.

Nelson HH, Wilkojmen M, Marsit CJ, Kelsey KT (2005). TP53 mutation, allelism and survival in non-small cell lung cancer. Carcinogenesis, 26, 1770-3.

Nigro JM, Baker SJ, Preisinger AC, et al (1989). Mutations in the p53 gene occur in diverse human tumor types. Nature, 342, 705-8.

Papadakis ED, Soulitzis N, Spandidos DA (2002). Association of 553 codon 72 polymorphism with advanced lung cancer: the Arg allele is preferentially retained in tumours arising in Arg/Pro germline heterozygotes. Br J Cancer, 87, 1013-8.

Park JY, Lee SY, Jeon H-S, et al (2002). Lys751Gln polymorphism in the DNA repair gene XPD and risk of primary lung cancer. 
Lung Cancer, 36, 15-16.

Steliga MA, Dresler CM (2011). Epidemiology of lung cancer: smoking, secondhand smoke, and genetics. Surg Oncol Clin N Am, 20, 605-18.

Szymanowska A, Jassem E, Dziadziuszko R, et al (2006). Increased risk of non-small cell lung cancer and frequency of somatic TP53 gene mutations in Pro72 carriers of TP53 Arg72Pro polymorphism. Lung Cancer, 52, 9-14.

Takahashi T, Nau MM, Chiba I, et al (1989). p53: a frequent target for genetic abnormalities in lung cancer. Science, 246, 491-4.

Torok S, Hegedus B, Laszlo V, et al (2011). Lung cancer in never smokers. Future Oncol, 7, 1195-211.

Travis WD (2011). Pathology of lung cancer. Clin Chest Med, 32, 669-92.

Uddin AFMK, Khan ZJ, Islam J, Mahmud A (2013). Cancer care scenario in Bangladesh. South Asian J Cancer, 2, 102-4.

Vousden KH (2000). p53: death star. Cell, 103, 691-4.

Wang YC, Chen CY, Chen SK, Chang YY, Lin P (1999). p53 codon 72 polymorphism in Taiwanese lung cancer patients: association with lung cancer susceptibility and prognosis. Clin Cancer Res, 5, 129-34.

Wang S, Lan X, Tan S, Wang S, Li Y (2013). P53 codon 72 Arg/ Pro polymorphism and lung cancer risk in Asians: an updated meta-analysis. Tumour Biol, 34, 2511-20.

Weston A, Perrin LS, Forrester K, et al (1992). Allelic frequency of a p53 polymorphism in human lung cancer. Cancer Epidemiol Biomarkers Prev, 1, 481-3.

WHO: World Health Organization (2017). World Health Rankings. Bangladesh: Lung Cancers. [Available from: https://www.worldlifeexpectancy.com/bangladesh-lungcancers; Last accessed: March 28, 2020].

WMA: World Medical Association (2013). World medical association declaration of helsinki ethical principles for medical research involving human subjects. JAMA, $\mathbf{3 1 0}$, 2191-4.

Yokota J, Kohno T (2004). Molecular footprints of human lung cancer progression. Cancer Sci, 95, 197-204.

Zhou W, Liu G, Miller DP, et al (2002). Gene-environment interaction for the ERCC2 polymorphisms and cumulative cigarette smoking exposure in lung cancer. Cancer Res, 62, 1377-81.

Zhou W, Liu G, Miller DP, et al (2003). Polymorphisms in the DNA repair genes XRCC1 and ERCC2, smoking, and lung cancer risk. Cancer Epidemiol Biomarkers Prev, 12, 359-65.

This work is licensed under a Creative Commons AttributionNon Commercial 4.0 International License. 